\title{
NUMERICAL AND EXPERIMENTAL INVESTIGATION OF WIND FLOW IN URBAN AREA
}

\author{
O. Hubova ${ }^{*}$, M. Macak ${ }^{* *}$
}

\begin{abstract}
The analysis presented in this paper is a preliminary modeling of the wind flow at the site of the planned complex of high-rise buildings using FLUENT ANSYS program. The high-rise buildings in built-up area affect the surrounding pedestrian level and also wind comfort on the terraces and on corners and crossing passages. We indicated the high wind speed areas for discomfort under strong wind condition experimentally in the aerodynamic tunnel with boundary layer in Bratislava and using CFD simulation taking into account the existing and planned buildings configuration. We also solved the task on the selected object in a simplified way according to the valid EN 1991-1-4 and NA standards. Local suction extremes, which are slightly higher than the standard, appeared at wind directions that are common in the area, i.e. the north and west winds.
\end{abstract}

Keywords: wind pressure coefficient, reference wind velocity, wind direction, roughness length, effective wind velocity, pedestrian wind comfort

\section{Introduction}

The effects and wind loads on the structures are given by EN 1991-1-4 and by the National Annex EN 1991-1-4/NA of the particular country which takes into account the meteorological conditions of the locality where the objects are located. It takes into account a specific windy situation in territory, where the buildings will be built. The resulting wind load values are affected by the following factors:

1 / wind conditions of a particular location, 2/ roughness of the terrain, 3/ aerodynamic characteristics of the shape of the object, 4 / sizes and shapes of surrounding objects.

Wind actions on structures are determined by wind pressure on surfaces. Wind pressure acting on the external surfaces depends on pressure coefficient $c_{\mathrm{pe}}$ for external pressure. For general shapes of structures, it is possible to find the values in Section 7 EN 1991-1-4. Pressure coefficients for atypical shapes of buildings are not mentioned in the standard. The wind pressure distribution on these structures can be obtained by experimental measurements in the boundary layer wind tunnel (BLWT) or by CFD simulation for a suitable model of turbulence.

\section{Numerical simulation of wind effect to the complex of buildings}

Computer fluid simulation for the complex of building was made in scale 1:1. We calculated results of external pressure coefficients on high-rise buildings for different wind directions and configuration of building areas and pedestrian wind comfort on the terraces and the entrances and exits to the subway and area between high-rise buildings. The step for rotating wind direction was $22.5^{\circ}$.

\footnotetext{
* Assoc. Prof. Ing. Olga Hubova, PhD.: Faculty of Civil Engineering, Department of Structural Mechanics, Slovak University of Technology Bratislava; Radlinskeho 11; 81005 Bratislava; SK, olga.hubova@stuba.sk

** Ing. Marek Macak, PhD.: Faculty of Civil Engineering, Department of Mathematics, Slovak University of Technology Bratislava; Radlinskeho 11; 81005 Bratislava; SK, marek.macaka@stuba.sk
} 


\subsection{Numerical model}

For the analysis of our problem we chose finite the volume method implemented into program ANSYS Fluent (2017). ANSYS Fluent offers several turbulence models. RANS model SST k- $\omega$ model was chosen. This model incorporates modifications for low-Reynolds number effects, compressibility, and shear flow spreading. The sensitivity of the solutions to values for $\mathrm{k}$ and $\omega$ outside the shear layer was improved.

The first transported variable is turbulent kinetic energy, $\mathrm{k}$ with equation

$$
\frac{\partial k}{\partial t}+\frac{\partial k u_{i}}{\partial x_{i}}=\tau_{i j} \frac{\partial u_{i}}{\partial x_{j}}-\beta^{*} k \omega+\frac{\partial}{\partial x_{j}}\left[v+\sigma^{*} v_{T} \frac{\partial k}{\partial x_{j}}\right] .
$$

The second transported variable in this case is the specific dissipation, $\omega$ with equation

$$
\frac{\partial \omega}{\partial t}+\frac{\partial \omega u_{i}}{\partial x_{i}}=\alpha \frac{\varepsilon}{k} \tau_{i j} \frac{\partial u_{i}}{\partial x_{j}}-\beta \omega^{2}+\frac{\partial}{\partial x_{j}}\left[v+\sigma v_{T} \frac{\partial k}{\partial x_{j}}\right],
$$

where $\beta^{*}, \sigma^{*}, \alpha, \beta$ and $\sigma$ are empirical constants.

\subsection{Computational domain}

Model of buildings was created according to provided DWG file. Size of the computational domain was $2 \times 1.6 \times 0.8 \mathrm{~km}^{3}(\mathrm{l} \times \mathrm{w} \times \mathrm{h})$ according to recommended maximum value of block ratio $3 \%$ by Franke (2007) and Tominaga (2008). The distance from the triangle object to the inlet, sides and top of the domain was at least five times the height of the building, and the distance from the outlet was at least eleven times the height, according to the guidelines by Franke (2007) and Tominaga (2008). We created two different computational domains according to different buildings configurations:

1/ Future buildings configurations (according to DWG), 2/ Existing buildings configurations.

\subsection{Computational grid (Mesh)}

We created mesh with size function set on distance using polyhedral elements. The element size on surface of the investigated building was $1 \mathrm{~m}$ with soft behavior using curvature function and inflation for these surfaces was applied with 5 layers with the height of the first layer $0.4 \mathrm{~m}$. The element size on surfaces of the surrounding buildings and entrance to the subway was $2 \mathrm{~m}$ with soft behavior using curvature function. The element size on another surface was $10 \mathrm{~m}$ with soft behavior using distance and curvature function. Inflation with 5 layers applied on bottom boundary with the height of the first layer 0.4 m. 4581744 nodes were generated. Computational grid is illustrated in Figure 1.

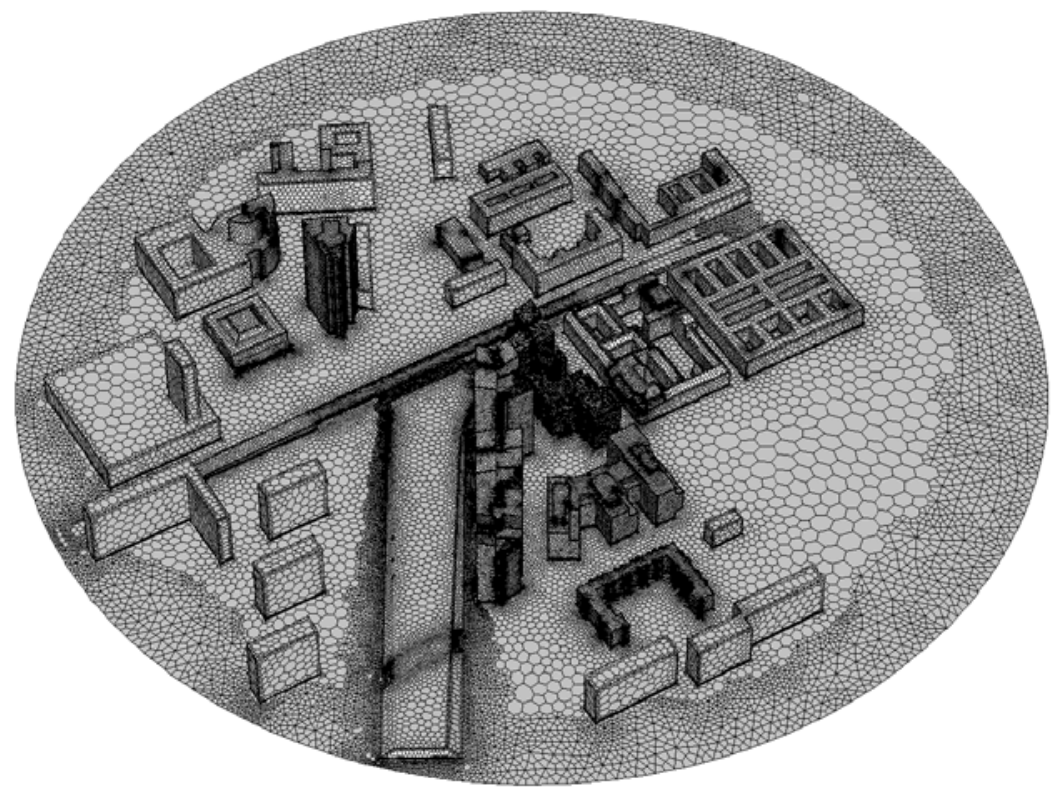

Fig. 1: Computational grid of urban area for future buildings configuration. 


\subsection{Boundary conditions}

The inlet boundary conditions of the domain are defined by the vertical profiles

$$
v(z)=\frac{v^{*}}{\kappa} \ln \frac{z+z_{0}}{z_{0}}, v^{*}=\frac{v_{r e f} \kappa}{\ln \frac{z_{r e f}+z_{0}}{z_{0}}},
$$

where $v(z)$ is mean wind velocity at height $z, v^{*}$ is shear velocity, $z_{0}$ is aerodynamic roughness height $\left(z_{0}=0.7\right), \kappa$ is von Karman constant $(\kappa=0.42), v_{\text {ref }}$ is the known wind speed:

- $\quad$ for external pressure computations $23.6 \mathrm{~m} / \mathrm{s}$ at a reference height $z_{\text {ref }}=10 \mathrm{~m}$,

- $\quad$ for pedestrian wind comfort computations $10 \mathrm{~m} / \mathrm{s}$ at a reference height $z_{\text {ref }}=100 \mathrm{~m}$.

Additional inputs for $k-\omega$ model are equation for turbulent kinetic energy $\mathrm{k}$, and specific turbulence dissipation rate $\omega$ as follows:

$$
k=\frac{u^{* 2}}{\sqrt{C_{\mu}}} \text { and } \omega(z)=\frac{\varepsilon(z)}{k},
$$

where $C_{\mu}=0.09$ is a model constant and $\varepsilon(z)=\frac{u^{* 3}}{\kappa\left(z+z_{0}\right)}$.

The outlet boundary is defined as pressure outflow and the side and upper boundary as zero gradients (symmetry).

\subsection{Achieved results}

The external wind pressure coefficients are shown in Table 1 for investigated wind directions and highlighted values that exceed the norms of the external pressure or suction coefficients. According to the standard, the external suction coefficients achieve the values at the walls and corners $c_{\mathrm{pe}}=-1.6$.

Tab. 1: External wind pressure for different wind direction

\begin{tabular}{ccccc}
\hline $\begin{array}{c}\text { Wind } \\
\text { direction }\left[{ }^{\circ}\right]\end{array}$ & Max we $_{\mathrm{e}}[\mathrm{Pa}]$ & Min $\mathrm{w}_{\mathrm{e}}[\mathrm{Pa}]$ & $\mathrm{C}_{\mathrm{pe} \_ \text {max }}[]$ & $\mathrm{C}_{\mathrm{pe}-\min }[\mathrm{]}$ \\
\hline 45 & 911.067 & -2206.751 & 0.959 & -2.323 \\
\hline 67.5 & 480.418 & -1040.464 & 0.506 & -1.095 \\
\hline 90 & 413.995 & -2454.819 & 0.436 & -2.584 \\
\hline 112.5 & 436.869 & -1760.222 & 0.460 & -1.853 \\
\hline 135 & 720.563 & -1569.240 & 0.758 & -1.652 \\
\hline
\end{tabular}



Fig.2: Peak velocity pressures distribution - wind direction $90^{\circ}$. 


\section{Experimental measurements in BLWT}

Models in scale 1:300 have been selected for the study (see Fig. 3). At this scale, the model of high-rise building and surrounding allows a good representation of the details. Repeated measurements in $120 \mathrm{~s}$ intervals on the model, corresponding to 300 minutes in real scale, were performed at varying barometric pressure $\mathrm{p}_{\mathrm{ba}}$ and temperature and thus the change in the value $\rho$, were recorded continuously. Measurements were performed at two reference speeds, $\mathrm{v}_{\text {ref }, 1}=8.72 \mathrm{~m} / \mathrm{s}, \mathrm{v}_{\text {ref }, 2}=10.7 \mathrm{~m} / \mathrm{s}$.
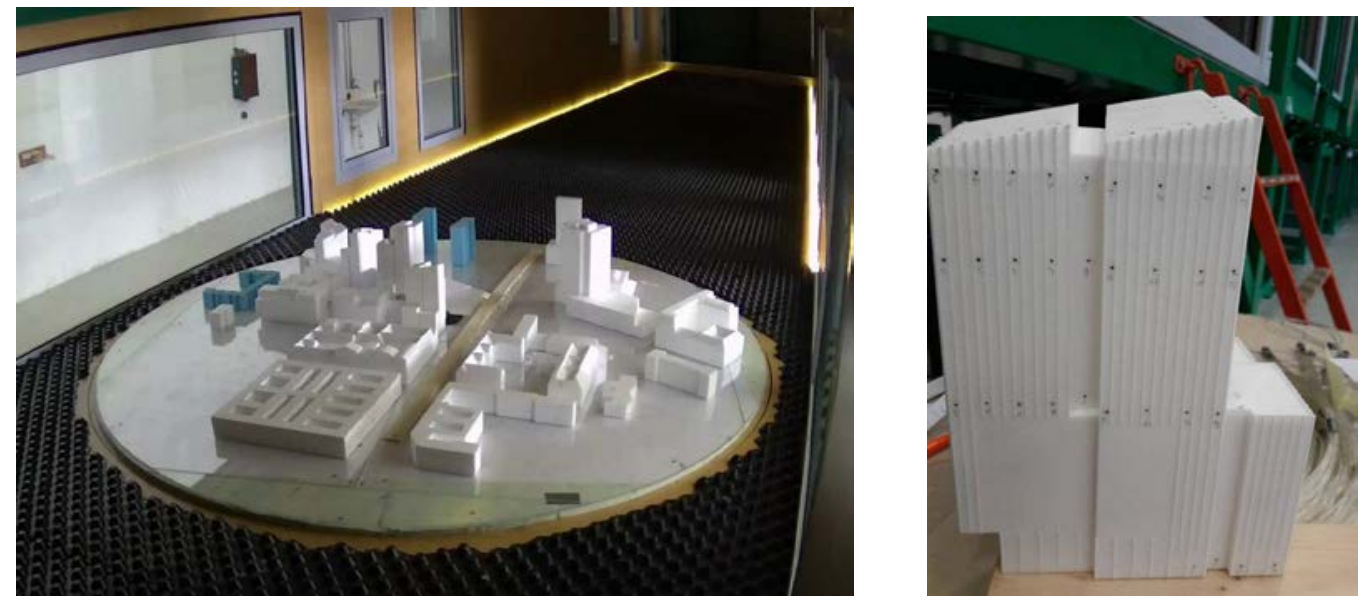

Fig.3: View of models located on the turntable - northern wind flows, detail of high-rise building.

\section{Conclusions}

Comparing results of CFD Simulation for complete future built-up area and experimental measurement, we can see that extreme suction values appeared in the same flow directions $45^{\circ}, 67.5^{\circ}, 112.5^{\circ}$ and pressures in $180^{\circ}$. Suction occurred on roofs in $90^{\circ}, 225^{\circ}$ and $270^{\circ}$ wind directions.

Local suction extremes, which are slightly higher than the standard, appear at wind directions that are common in the area, i.e. the north and west winds. The most unusual values appeared on the corners and on the roof of the building. The flow is modified by surrounding objects and therefore wind pressure higher than in EN 1991-1-4 may occur locally on an area less than $1 \mathrm{~m}^{2}$.

Resulting local values of the external pressure and suction of wind obtained by CFD simulation showed at the corner under the terrace values of suction $\mathrm{w}_{\mathrm{e}}=-1.76 \mathrm{kPa}$ for the south-east flow; and $\mathrm{w}_{\mathrm{e}}=-2.45 \mathrm{kPa}$, for the east flow. On the roof of building the external suction reached $\mathrm{w}_{\mathrm{e}}=-2.2 \mathrm{kPa}$ for north-east flow. The values obtained by the CFD simulation were higher than the values from the experimental measurements were caused by inadequate considering of the roughness of the building surface.

\section{Acknowledgement}

This paper was created with the support of VEGA grants No. 1/0265/16. This paper was created with the support of the TU1304 COST action "WINERCOST".

\section{References}

ANSYS Inc., ANSYS Fluent Theory Guide, Release 18.1 (2017).

ANSYS Inc., ANSYS Fluent User's Guide, Release 18.1 (2017).

ASCE Mannuals and Reports on Engineering Practice, no.67 (1999) Wind Tunnel Studies of Buildings and Structures. Library of Congress Catalog Card No. 98-44103, USA, ISBN 0-7844-0319-8.

EN 1991-1-4: Eurocode 1: 2005. Action on structures - Part 1-4: General actions - Wind actions.

Franke, J. et al., (2007) Best practice guideline for the CFD simulation of flows in the urban environment, COST Office Brussels.

Hubova, O., Lobotka, P., (2014) The Natural Wind Simulations in the BLWT STU Wind Tunnel, in: Porceedings of ATF 3nd Conference on Building Physics and Applied Technology in Architecture and Building Structures. E Book of reviewed papers, May 6-7, 2014, Austria, Vienna, pp. 78-84, ISBN 978-3-200-03644-4.

Tominaga, Y., (2008) AIJ guidelines for practical applications of CFD to pedestrian wind environment around buildings, J Wind Eng Ind Aerod 2008. 96, (10-11) 1749-1761. 